Mongolian Academy of Sciences
Mongolian Journal of Chemistry
Institute of Chemistry \& Chemical Technology

\title{
Fatty acid, Tocopherol and Sterol Composition in Sea buckthorn (Hippophae rhamnoides L.) of Mongolia
}

\author{
Otgonbayar.Ch ${ }^{1}$, B.Matthaus ${ }^{2}$, P.Odonmajig ${ }^{1}$ \\ ${ }^{1}$ Institute of Chemistry and Chemical Technology, MAS \\ ${ }^{2}$ Max Rubner-Institute, Detmold, Germany
}

\begin{abstract}
Absract: The content and composition of lipids isolated from seed and pulp of sea buckthorn were investigated. Fatty acids and sterols were analyzed by CGC while tocopherols were analyzed by HPLC. $12.67 \%$ glyceride was found in the seed. The oil of sea buckthorn seed oil showed low lewels of saturated fatty acids in comparison with the buckthorn pulp oil. Palmitic (7.13\%), oleic $(15.85 \%)$, linoleic $(36.9 \%)$ and linolenic acids $(31.11 \%)$ predominated in the seed oil. Palmitic $(29.17 \%)$, palmitoleic $(32.86 \%)$, oleic $(4.92 \%)$, vaccenic $(9.35 \%)$ and linoleic $(16.08 \%)$ fatty acid was dominating in the pulp oil. The primary tocopherol of sea buckthorn seed and pulp oil were $\alpha-$ tocopherol and $\gamma$-tocopherol $(46.54 \mathrm{mg} / 100 \mathrm{~g}, \quad 59.02 \mathrm{mg} / 100 \mathrm{~g})$. Seed oil contains more $(94.34 \mathrm{mg} / 100 \mathrm{~g})$ total sterols than pulp $(90.25 \mathrm{mg} / 100 \mathrm{~g})$ oil.
\end{abstract}

Keywords: Hippophae rhamnoide, seed oil, pulp oil, fatty acids, tocopherols, sterols

\section{Introduction}

$\mathrm{H}$ ppophae (sea buckthorn) is a deciduous spiny shrub or small tree between two to four meter high, widely distributed throughout the temperate zone of Asia and Europe. The fruit characteristics, Asiatic geographical distribution and cultural practices of sea buckthorn are reviewed [1]. Sea buckthorn (Hippophae rhamnoides) is one of the important natural resources of the mountainous regions of China and Russia. The plant grows naturally in sandy soil at an altitude of 1,200-4,500 meters (4,000-14,000 feet) in cold climates, though it can be cultivated at lower altitudes and in temperate zones. Recently it has been extensively planted across much of northern China, and in other countries, to prevent soil erosion and to serve as an economic resource for food and medicine products. Mongolia has invested in planting sea buckthorn, in the 2000s. The oil is obtained from the whole berries, pulp or seeds. Seed or pulp oil is usually yellow in color represented by the occurrence of large amount of carotenoids [2,3]. The literature describing the role of Hippophae in prevention and control of cancer is inadequate, however certain analysis the known experimental research information on anticancer by Hippophae available at present [4]. The oil of sea buckthorn has general nourishing, revitalizing, and restorative action. It can be used for treatment of acne, dermatitis, irritated, dry itching skin, sore skin, skin ulcers, burns, scalds, cuts and tissue regeneration. Sea buckthorn oil effectively combats wrinkles, dryness and other symptoms of malnourished or prematurely aging skin and is utilized in anti aging skin creams and lotions $(5,6)$. Sea buckthorn oil is one of the most imperative products obtained from the sea buckthorn seed and pulp is now commercially very important. 
The results indicate that the oil from the seed and pulp have identical quality except in Vitamin E (tocopherol) content. In recent years, sea buckthorn has become an important raw material of health products and cosmetics, especially in China and Russia. This exploitation is based on more than one thousand years application in Tibetan, Mongolian and Chinese traditional medicine (7). Plant seed oil contain tocopherol and tocotrienols, which are used as natural antioxidands and vitamin E. Tocopherols are present in oil seeds, leaves, and other green parts of higher plants [8]. The antioxidant activity increases for tocopherois and tocotrienols in the order $\alpha$ to $\delta$, whereas the biological activity is inversely proportional to the antioxidant activity [9]. Several studies reported the effect of tocopherols on the oxidative stability of oils and different lipid systems [10]. It has not been studied precisely the composition of sea buckthorn growing in Mongolia. Therefore, the aim of this work was to determine the tocopherols, tocotrienols, sterols and fatty acid composition of Mongolian sea buckthorn.

\section{Experimental \\ Materials}

All solvents used were of analytical grade: $n$ hexane, n-heptane, diethyl ether, ethanol and methanol were acquired from Merck, Darmstadt, Germany.

Seed Berries of Hippophae rhamnoides were collected in Zavhan aimak in August 2010.

Oil Extraction. The stored oil seeds were crushed and ground with a grinding mill (Petra electric, Burga, Germany). The oil was extracted from the ground material by extraction with n-hexane at $50-60^{\circ} \mathrm{C}$ in a Soxhlet apparatus for $6 \mathrm{~h}$ [11]. The oil content was determined as a percentage of the extracted oil to the sample weight (w/w). The samples were analyzed in triplicate, and then means and the standard deviations were calculated. The oil obtained was stored at $4{ }^{0} \mathrm{C}$ for further investigation.

Fatty Acid Compotision. The fatty acid composition was determined according to the the International Organization of Standards (ISO) draft standard [12]. One drop of the oil was dissolved in $1 \mathrm{ml}$ of $\mathrm{n}$-heptane, $50 \mu 12 \mathrm{M}$ sodium in methanolate in methanol was added, and the closed tube in was agitated vigorously for $1 \mathrm{~min}$. After addition of $100 \mu \mathrm{l}$ of water, the tube was centrifuged at $4000 \mathrm{xg}$ for $10 \mathrm{~min}$ and the lower aqueous phase was removed. Fifty (50) $\mu 11 \mathrm{M}$ HCI was added to the heptane phase, the two phases were mixed for a short time and the lower aqueous phase was rejected. About $20 \mathrm{mg}$ of sodium hydrogen sulfate (monohydrate, extra pure, Merck, Darmstadt, Germany) was added, and after centrifugation at $4000 \mathrm{xg}$ for $10 \mathrm{~min}$ the top n-heptane phase was transferred to a vial and injected into a Varian 5890 gas chromatograph with a capillary column, CPSil 88, (100 m long, $0.25 \mathrm{~mm}$ ID, film thickness $0.2 \mu \mathrm{m})$. The temperature program was: from $155^{\circ} \mathrm{C}$ heated to $220^{\circ} \mathrm{C}$ $\left(1.5^{\circ} \mathrm{C} / \mathrm{min}\right), 10 \mathrm{~min}$ isotherm; injector $250^{\circ} \mathrm{C}$, detector $250^{\circ} \mathrm{C}$, carrier gas $1.07 \mathrm{ml} / \mathrm{min}$ hydrogen, split ratio 1:50, detector gas 30 $\mathrm{ml} / \mathrm{min}$ hydrogen; $300 \mathrm{ml} / \mathrm{min}$ air and 30 $\mathrm{ml} / \mathrm{min}$ nitrogen, manual injection, volume less than $1 \mu l$. The integration software computed the peak areas and percentages of fatty acid methyl esters (FAME) were obtained as weight percent by direct internal normalization.

Tocopherols. Solutions of $250 \mathrm{mg}$ oil in 25 $\mathrm{ml}$ n-heptane were prepared for used for HPLC analysis of tocopherols. The HPLC analysis was conducted using a MerckHitachi low pressure gradient system, fitted with a L-6000 pump, a Merck-Hitachi F-1000 Fluorescence Spectrophotometer (detector wavelengths for excitation $295 \mathrm{~nm}$, for emission $330 \mathrm{~nm}$ ) and a D-2500 integration system. $20 \mathrm{ml}$ of the samples were injected by a Merck 655-A40 Autosampler onto a Diol phase HPLC column $25 \mathrm{~cm}$ x $4.6 \mathrm{~mm}$ ID (Merck, Darmstadt, Germany) used with a flow rate of $1.3 \mathrm{ml} / \mathrm{min}$. The mobile phase used was n-heptane/tert-butyl methyl ether $(99+1 /$, v/v) [13].

Sterols. The sterol compositions of sea buckthorn pulp and seed oils were determined by silylation with $\mathrm{N}$-methyl-N-trimethyl-silylheptafluorobutyramide, and the assignments were made by using the retention times (RTs) of the individual sterols and calculation of the relative RTs in relation to betulin as an internal standard following the ISO/FIDS [14] 
draft standard. In brief, $250 \mathrm{mg}$ of oil was saponified with a solution of ethanolic potassium hydroxide by boiling under reflux. The unsaponifiable matter was isolated by solid-phase extraction on an aluminium oxide column (Merck) on which fatty acid anions were retained and sterols passed through. The sterol fraction from the unsaponifiable matter was separated by thin-layer chromatography (TLC) on $20 \times 20 \mathrm{~cm}$ silica gel plates of 0.25 $\mathrm{lm}$ layer thickness using hexane/diethyl ether $(1 / 1[\mathrm{v} / \mathrm{v}])$ as the developing solvent (Merck). After re-extraction from the TLC material, the compositions of the sterol fractions were determined by capillary gas chromatography (HP 5890 A unit with FID) using betulin as an internal standard. The compounds were separated on an SE 54 CB (Macherey-Nagel, Duren, Germany) (50-m long, 0.32-mm I.D., $0.25-\mathrm{mm}$ film thickness). Further parameters were hydrogen as carrier gas; split ratio, 1:20; injection and detection temperature adjusted to $320^{\circ} \mathrm{C}$; temperature program, $245-260^{\circ} \mathrm{C}$ at $5^{\circ} \mathrm{C} /$ minutes.

The free and esterified sterols were separated from the other oil constituents by preparative TLC on Silica gel 60 G "Merck" and mobile phase n-hexane: diethyl ether 1:1 v/v. The esterified sterols were saponified with ethanolic $\mathrm{KOH}$, extracted and purified by TLC. The quantitative evaluation and individual composition was determined by gas chromatography (Homberg and Bielefeld, 1989), using HP 5890 A unit with FID, 25 m capillary column impregnated with OV-17 and conditions as follows: column temperature $260-300^{\circ} \mathrm{C}$, with a change $6^{\circ} \mathrm{C} / \mathrm{min}$, detector temperature $320^{\circ} \mathrm{C}$, injector temperature $300^{\circ} \mathrm{C}$, gas carrier - nitrogen.

\section{Results and discussion}

Sea buckthorn seed oil is an excellent source of essential fatty acids, making up approximately 70 percent of its composition. Sea buckthorn oil is traditionally used in the treatment of gastric ulcers, and laboratory studies confirm the efficacy of the seed oil for this application (9). Sea buckthorn seed and pulp oils were analysed for different characteristics and are shown in Table 1. The results indicate that the oils from the seed and pulp have identical quality except in fatty acids, vitamin E (tocopherol) and sterol content. In the present study, it was observed that among the seed and pulp oil assayed for their vitamin E content, the seed oil exhibited high content than the pulp oil.

Three major fatty acids namely oleic, linoleic and linolenic acid were in the seed extracted with n-hexane. This fatty acid comprised more than $83.86 \%$ of total fatty acids (Table 1). The latter two acids were predominant fatty acids with contents of $36.9 \%$ and $31.11 \%$, respectively.

Table 1. Fatty acid composition in sea buckthorn seed and pulp oil

\begin{tabular}{|c|c|c|}
\hline \multirow{2}{*}{ Fatty acid } & \multicolumn{2}{|c|}{ Quantity, \% } \\
\hline & Seed oil & Pulp oil \\
\hline Oil content $(\%)$ & 12.67 & (oil) \\
\hline $14: 0$ & 0.11 & 0.5 \\
\hline $16: 0$ & 7.13 & 29.17 \\
\hline $16: 1 n-9$ & 2.21 & 32.86 \\
\hline $17: 0$ & 0.04 & 0.04 \\
\hline 18:0 & 2.58 & 0.05 \\
\hline $18: 1 \mathrm{n}-9$ & 15.85 & 4.92 \\
\hline $18: 1 n-11$ & 1.99 & 9.35 \\
\hline $18: 2 n-6$ & 36.9 & 16.08 \\
\hline $18: 3$ n-9,12,15 & 31.11 & 1.49 \\
\hline $20: 0$ & 0.37 & 0.42 \\
\hline $20: 1 \mathrm{n}-9$ & 0.25 & 0.06 \\
\hline $20: 2 \mathrm{n}-11,13$ & 0.08 & 0.03 \\
\hline $22: 0$ & 0.11 & 0.23 \\
\hline $24: 0$ & 0.04 & 0.12 \\
\hline Unsaturated FA & 88.39 & 64.79 \\
\hline Saturated FA & 10.38 & 30.53 \\
\hline
\end{tabular}

Palmitic and palmitoleic acid were the predominant fatty acids in the sea buckthorn pulp oil. Contents of both fatty acids to the pulp in the sea buckthorn were $29.17 \%$ and $32.86 \%$, respectively. Lipids from the pulp of sea buckthorn were characterized by high concentrations (up to 29.17\%) of saturated fatty acids (comprised primary of palmitic acids) and high concentrations of unsaturated fatty acids such as palmitoleic acid (32.86\%). The pulp oil contains several unusual fatty acids, oleic $(4.92 \%)$, vaccenic $(9.35 \%)$, linoleic (16.08\%) and linolenic acids (1.49\%). The contents and compositions of tocopherols, tocotrienols were determined. In table 2 presented sum of Vitamin $\mathrm{E}$ in the seed oils were characteristic for commonly used vegetable oils (100 to $1000 \mathrm{mg} / \mathrm{kg}$ ). 
Table 2. Tocopherol and tocotrienol concentrations (mg/100g oil) in sea buckthorn seed and pulp oil

\begin{tabular}{|c|c|c|}
\hline Constituent & Seed oil & Pulp oil \\
\hline$\alpha$ - tocopherol & 34.57 & 59.02 \\
\hline$\alpha$-tocotrienol & 2.17 & 2.32 \\
\hline$\beta$-tocopherol & 5.95 & 5.63 \\
\hline$\gamma$-tocopherol & 46.54 & 4.37 \\
\hline Plastochromanol & 0.88 & 7.42 \\
\hline$\gamma$-tocotrinol & 0 & 4.99 \\
\hline$\Delta$-tocopherol & 4.23 & 6.5 \\
\hline Total tocopherol & 94.34 & 90.25 \\
\hline
\end{tabular}

The total tocopherol content in the seed and pulp oil were $94.34 \mathrm{mg} / 100 \mathrm{~g}$ and $90.25 \mathrm{mg} / 100 \mathrm{~g}$ of oil. $\alpha$-Tocopherol was the predominant tocopherol found in the oil. Sea buckthorn seed and pulp oil contained amounts of vitamin E $(34.57 \mathrm{mg} / 100 \mathrm{~g}$ oil, $59.02 \mathrm{mg} / 100 \mathrm{~g}$ oil) that could be interesting in the production of naturally occurring tocopherols and tocotrienols for the stabilization of fats and oils against oxidative deterioration or for application in dietary, pharmaceutical, or biomedical products. Sterol contents of sea buckthorn seed pulp oil are given in Table 3. The concentration of total sterols contains $11418.0 \mathrm{mg} / 100 \mathrm{~g}$ in seed oil and $4055.33 \mathrm{mg} / 100 \mathrm{~g}$ in pulp oil.

Table 3. Sterol composition (mg/100g oil) in sea buckthorn seed and pulp oil

\begin{tabular}{|l|c|c|}
\hline \multicolumn{1}{|c|}{ Constituent } & Seed oil & Pulp oil \\
\hline Cholesterin & 0.2 & 0.49 \\
\hline Brassicasterin & 0.04 & 0.07 \\
\hline 24-Methylencholesterin & - & 2.88 \\
\hline Campesterin & 2.22 & 2.62 \\
\hline Campestanol & 0.29 & 0.04 \\
\hline Stigmasterin & 2.2 & 0.69 \\
\hline 7-Campesterin & 24.74 & 0.77 \\
\hline Chlerosterin & 2.77 & 1.44 \\
\hline B-Sitosterin & 55.19 & 79.54 \\
\hline Sitostanol & - & 1.31 \\
\hline 5-Avenasterin & 9.97 & 1.81 \\
\hline 5,24-Stigmastadienol & 0.98 & 1.9 \\
\hline 7-Stigmastenol & 0.77 & 6.43 \\
\hline 7-Avenasterin & 0.64 & - \\
\hline Total (mg/kg) & 11418.0 & 4055.33 \\
\hline
\end{tabular}

B-Sitosterin $\quad(55.19 \mathrm{mg} / 100 \mathrm{~g} \quad$ oil, $79.54 \mathrm{mg} / 100 \mathrm{~g}$ oil) was the main component of sterol fraction, followed by 5-avenasterin $(9.97 \mathrm{mg} / 100 \mathrm{~g}$ oil, $\quad 1.81 \mathrm{mg} / 100 \mathrm{~g} \quad$ oil), chlerosterin $(2.77 \mathrm{mg} / 100 \mathrm{~g}$ oil, $1.44 \mathrm{mg} / 100 \mathrm{~g}$ oil) and campesterin $(2.22 \mathrm{mg} / 100 \mathrm{~g}$ oil, $2.62 \mathrm{mg} / 100 \mathrm{~g}$ oil), respectively.

\section{Conclusion}

Seed and pulp oil in Sea buckthorn (Hippophae rhamnoides L.) of Mongolia were analyzed to determine oil content, fatty acid and tocopherol and sterol composition. The total tocopherol content in the seed and pulp oil were $94.34 \mathrm{mg} / 100 \mathrm{~g}$ and $90.25 \mathrm{mg} / 100 \mathrm{~g}$ of oil.

\section{Acknowledgments}

Ch.O. acknowledges financial assistance by a DAAD grant during his three month stay in Germany.

\section{References}

1. Li. Tsc, Schroeder.W.R, Sea buckthorn (Hippophae rhamnoide): A multipurpose plant. Hort Technology, (1996) 6, 370-380

2. Jeppsson N, Gao. X.Q, Changes in the contents of kaempferol, duercetin and L-ascorbic acid in sea buckthorn berries during maturation. Agri Food Sci Finland (2000) 9. 17-22

3. Zeb.A, Mehmood.S, Carotenoid contents from various sources their potential health appliacations. Pak Nutrition, (2004) 3. 107-202

4. Zeb.A, Mehmood.S, The anti-cancer activities of Hippophae seed oil and its effect on the weight of the immunological organs. Hippophae (1989) 3. 31-34

5. Lanev, The effect of an extract of Seabuckthorn on the healing of experiment skin wounds in rats. Dermatology. (1995) 48(3), 30-33

6. Xing.J, Effect of Seabuckthorn seed and pulp oils on the experimental models of gastric ulcer in rats. Fitoterapia. (2002) 73(7-8), 644-650

7. Xu.M.Y, X.X.Sun, W.X.Tong, Medical Research and development of Seabuckthorn. Hippophae. (1994) 7, 32-40

8. Kamal-Eldin, Normal-Phase HPLC of Tocopherols and Tocotrienols, J.Chromatogr. 881:217-227 (2000)

9. Papas.A.M, Oil soluble antioxidant in Foods, Toxicol. Ind. Health 9: 123149 (1993) 
10. Huang.S.W, Frankel.E.N. Antioxidant activity of $\alpha$ - and $\gamma$-tocopherols in bulk oils and in oil in water emulsion. J. Agric. Food Chem. (1994) 42, 2108-2114

11. AOCS (1993) Official methods \& recommended practices of the American Oil Chemists Society, 4th edn, edited by AOCS. Champaign, IL Official Method Ai 2 75, reapproved (2006)
12. ISO International Standard 5509. Animal and vegetable fats and oilspreparation of methyl esters of fatty acids. (2000) ISO, Geneva

13. Balz.M, Shulte.E, Their.H.P, Trennung von tocopherol und tocotrienolen durch HPLC. Fat Sci Technol (1992) 94:209-213

14. ISO/FIDS 5509. International Standards, (1997) 1st edn, Geneve, Switzerland 